\title{
Seeking unconventional alliances and bridging innovations in spaces for transformative change: the seed sector and agricultural sustainability in Argentina
}

Patrick van Zwanenberg $^{1,2,3,4}$, Almendra Cremaschi $^{2,3,4}$, Martin Obaval $^{1,2,3,4}$, Anabel Marin ${ }^{1,2,3,4}$ and Vanesa Lowenstein $^{2,3,4,5}$

\begin{abstract}
Experimental spaces for learning about and nurturing processes of social-ecological transformation are of increasing interest; a reflection, in part, of a more interventionist approach to sustainability research and funding. We reflect on our experience in Argentina facilitating a multistakeholder transformative space to identify and discuss agricultural sustainability challenges associated with seed market concentration, and to explore social innovations in the seed sector that can help foster more sustainable pathways of change in agricultural systems. We argue that in facilitating such a process, it is important to understand the diversity of perspectives on the meanings and functions of seed systems, the agricultural sustainability challenges those systems give rise to and of potential solutions, and to work with and from those divergent perspectives to identify areas of actionable consensus or potential affinities between actors who otherwise understand or prioritize agricultural sustainability in different ways. We suggest that ideas for intervention that are able to exploit common ground are more likely to be politically and practically viable. We illustrate this claim with a proposal for an open source seed licensing system, which potentially addresses distinctive concerns about strict intellectual property rules on the part of domestic seed breeders, farmers, rural social movements, and parts of government, who otherwise adopt different perspectives on desired agricultural futures. We suggest that this kind of bridging innovation may help to reconfigure social relations around seed systems in ways that can open up space for more sustainable pathways of agricultural change.
\end{abstract}

Key Words: Argentina; seeds; sustainability; $t$-labs; transformative spaces

\section{INTRODUCTION}

Over the last three decades, an unprecedented process of concentration in world and regional seed markets has been underway, a phenomenon closely associated with the emergence of new genomics-based technologies and the world-wide diffusion of strict intellectual property rights over biological material, pushed in large part though global, regional, and bilateral trade agreements (Newell and Mackenzie 2004, Schenkelaars et al. 2011). In the process, global seed research and development (R\&D), once widely distributed over hundreds of medium and large seed firms and public sector institutions, is becoming increasingly concentrated in just five or six multinational agrochemical firms (Howard 2015). The long-term consequences of this ongoing restructuring of the seed sector are still unclear, but are likely to involve the loss of different forms of diversity in agricultural systems via restrictions on the free circulation of germplasm, the decline or even outright loss of domestic seed breeding capabilities in some jurisdictions, concentration of R\&D resources on fewer plant species and crop production constraints, declining agricultural biodiversity, and a less diverse range of agricultural production practices that the seed sector is able to support (Piesse and Thirtle 2010; Tang, Matson, and Wynn, unpublished manuscript).

This set of issues was the focus for a transformation laboratory (T-Lab) that we organized in Argentina, a major agricultural producer and exporter. Through a T-Lab based process, we are seeking to facilitate a transformative space in which actors involved in governing, producing, and using seeds can identify and explore emerging sustainability challenges associated with market concentration in the seed sector (i.e., linked challenges of economic development, social justice, and ecological integrity), and design and test social innovations that can help foster more sustainable pathways of change in seed and agricultural systems. T-Labs, and other similar ideas, such as social innovation labs and change labs are experimental spaces in which people with diverse backgrounds, perspectives, interests, and areas of expertise work together to understand complex systems and the problems they generate and to identify, codesign, and prototype novel ways of addressing the underlying causes of those problems (Westley et al. 2014, Gryszkiewicz et al. 2016, Olsson et al. 2017). We are part of a large international research network that is experimenting with knowledge/intervention coproduction processes for sustainability, treating T-Labs as sets of ideas to help us think about how transdisciplinary research can help understand and support transformative change processes.

We discuss the process through which we have sought to facilitate such an experimental transformative space in relation to seed systems in Argentina. In doing so, we emphasize two issues: (1) the importance of engaging explicitly with the knowledge politics of sustainability, i.e., the contested perspectives on what constitutes the principal sustainability challenges in the agricultural sector and on what more sustainable seed and agricultural system configurations ought to look like; and (2) the powerful processes of "lock in" to unsustainable agricultural systems and, accordingly, the politically marginalized position of actors who are experimenting with and seek to support radically alternative seed and agricultural practices. We argue that those challenges require attention to: (1) methods appropriate to

\footnotetext{
${ }^{1}$ National Research Council for Scientific and Technical Research (CONICET), ${ }^{2}$ Centro de Investigaciones para la Transformación (CENIT), ${ }^{3}$ STEPS América Latina, Buenos Aires, Argentina, ${ }^{4}$ Economic and Business School-Universidad Nacional de San Martín (UNSAM), ${ }^{5}$ University of Buenos Aires (CEIDIE)
} 
understanding competing perceptions and understandings of sustainability; and (2) strategies to identify areas of actionable consensus and potential affinities between actors who otherwise understand and prioritize sustainability challenges in different ways. The fostering of alliances and ideas for intervention that seek to exploit that common ground also requires attention.

\section{SPACES FOR TRANSFORMATIVE CHANGE}

Sustainability research and policy have placed increasing emphasis on the need to support and catalyze deliberate socialecological transformation as a response to the severe threats posed by global environmental change (O'Brien 2012, ISSC/UNESCO 2013, Future Earth 2014). At a general level, in this context, transformation refers to fundamental or nonlinear change in social-technical-ecological systems (Pelling et al. 2015), but there are many ways in which transformative change processes can be understood, and different perspectives on how, if at all, such processes can be supported, fostered, and/or purposefully directed in ways that deliver more ecologically sustainable and just social practices and outcomes (Scoones et al. 2015, Patterson et al. 2017).

Our own understanding is located, analytically, in the context of a quasi-evolutionary approach to understanding social-technical change (Rip and Kemp 1998, Stirling 2009). This involves appreciating that established agricultural production systems, like any large complex system, are the (intentional and emergent) outcome, i.e., a configuration, of diverse material, socioeconomic, institutional, and political elements. Mutual interdependencies between such elements, which range from specific artifacts and practices, through to bodies of knowledge and skills, to established markets and patterns of political and economic power, mean that system change tends to be incremental and highly path dependent.

Radically alternative ideas, say for more sustainable agricultural practices, are at a disadvantage; they typically do not fit well with the existing system configuration of agronomic knowledge, business models, input and output markets, patterns of land ownership, economic and state interests, and so on, which reproduce (and benefit from) established agricultural practices. Alternative ideas are seen as requiring protective space from the adverse selection pressures created by existing systems, both for actors to improve the performance of more sustainable practices, but also to try to develop new path-breaking system configurations (or to reconfigure existing systems), through which those practices can become part of broader, i.e., transformative, pathways of social-technical-ecological change (Rip and Kemp 1998, Smith 2007).

Given this analytical lens, deliberate efforts to catalyze and support processes of transformative change need to focus not only on interventions, which, in themselves, help to constitute, or directly support, in this case, more ecologically benign, economically resilient, and socially just forms of agricultural practice, but that also draw attention to the need for, promote learning about, and encourage broader system (re)configuration processes. The latter potentially involves a very wide range of activities, from challenging incumbent structures and practices to seeking political realignments between actors, from lobbying for supportive policy measures to creating new markets, and from fostering shifts in consumer and cultural norms to producing new kinds of knowledge (Smith et al. 2005, Stirling 2014). This is a highly challenging task.

Within the resilience tradition, a social-ecological transformations' approach (Patterson et al. 2017) draws, in part, on ideas from this evolutionary perspective to support deliberate efforts to catalyze and navigate social-ecological transformations (Olsson et al. 2017). Although initially focused on transformations in ecosystem stewardship, through innovation in governance and management systems, this approach has developed a more ambitious agenda in recent years, focusing on transformations in less geographically bounded, broader social-technical-ecological systems (Olsson et al. 2014). The claim is that disruptive social innovations with potential to foster system change can be nurtured by, and connected to, broader institutional resources and responses, and that institutional entrepreneurs can both help to leverage and scale up those initiatives and destabilize dominant systems (Westley et al. 2011, Moore et al. 2014).

Some resilience scholars have emphasized a role for social innovation labs, change labs, or T labs as sites for developing and experimenting with disruptive social innovations (Westley et al. 2012, 2014, Olsson et al. 2017). The nomenclature varies, but the core features of such labs are that they bring diverse participants together, focus on complex systems and the problems they generate, and foster an experimental, prototyping-based approach to addressing the root causes of those problems (Westley et al. 2012, 2014, Hassan 2014). Emphasis is placed on techniques to encourage transdisciplinary learning about, and a common understanding of, the nature of complex systems, the problems they generate, and what alternative, better systems might look like; to explore the transformative potential of different ideas for achieving system change, developing an appreciation of where human agency lies within such systems, of where there are leverage points, and an exploration of how candidate ideas can be put into practice (Westley et al. 2012, 2014).

T-Labs have been proposed as a variant of these kinds of experimental spaces; the key difference being that the focus is on coupled social-ecological problems, rather than social problems per se. Specifically, the idea is that T-lab processes explicitly consider the dynamic nature of the interactions between social systems and ecosystems, and recognize that change needs to be systemic and rapid, given the gravity of global environmental threats (Olsson et al. 2017). Thus far, however, there has been little practical experimentation with the idea of T-labs, and there is no specific literature that we are aware of.

In drawing on ideas about these experimental spaces, and in particular the core themes of collective deliberation about systemic problems, and the identification and testing of potentially transformative interventions, we highlight two issues that tend to be underemphasized, or at least underexplored, in the resilience literature on lab-based experimental spaces. The first of those concerns the sheer challenge of achieving a common understanding of the functions and meanings of particular socialtechnical systems, the sustainability problems those systems generate, and of desired social-technical-ecological futures (cf. O'Brien 2012, Scoones et al. 2015). The second concerns the powerful processes of "lock in" to large, unsustainable socialtechnical systems, emphasized strongly in the evolutionary 
literature, and in particular the (typically) politically marginalized position of actors experimenting with radically alternative ideas and practices, and who are seeking to foster structural change in well-established, incumbent systems (Smith and Stirling 2010, Pereira et al. 2015).

For us, these two issues underline the importance, when thinking about a facilitated transformative space, of recognizing and coping with multiple perspectives, in this case, about agricultural system sustainability, and their contestation, and of thinking carefully about how learning from that plurality of perspectives can help identify areas of actionable consensus among, and/or potential affinities between, actors and constituencies who otherwise adopt different perspectives on or priorities about agricultural sustainability. One reason for identifying areas of consensus is to try and foster potential alliances between actors who may have different views on what counts as a more sustainable configuration, but might nevertheless agree on some strategies or desired end points. Alliances or coalitions of actors are important because the actors and institutions that help to constitute and reproduce dominant agricultural systems are so powerful and command such a wide array of resources, that coalitions of actors and institutions in support of alternative pathways of change are likely to be required if alternatives are to be politically and practically viable (Schmitz and Scoones 2015, Newell 2015).

A reason for identifying potential affinities between actors is to explore candidate social innovations that can bridge divergent perspectives on sustainability and form unusual alliances. An example might be an intervention, say a policy initiative, that promises to help both reduce carbon emissions and boost regional industrial development, and thus might find support, for instance, across environmentalists, local government, and trade unions who might not otherwise share similar priorities about sustainability. An alternative way in which some innovations might have this kind of bridging effect is if the intervention prompts actors to appreciate or reinterpret their own interests and perspectives in slightly different ways. An example, from the energy sector, is the "feed in tariff" policy innovation that allows households, farms, and small businesses to sell excess renewable energy produced on their premises to the national grid, thus prompting those actors to reinterpret their interests in ways that create a broader coalition for renewable energy (Lockwood 2014). Again, the objective is to secure a broad political alliance of actors in favor of a more sustainable practice.

\section{CASE STUDY: THE SEED SECTOR AND ARGENTINEAN AGRICULTURE}

Argentina became integrated into the world economy during the 19 th century by producing and exporting agricultural products, and the agricultural sector remains hugely important. It is a major source of rents, tax revenue, and foreign currency earnings, with raw and processed agriculture products accounting for over $60 \%$ of total exports (Simoes et al. 2017). For much of the postwar period, the sector experienced a very slow rate of growth with sluggish adoption of the technologies associated with the Green Revolution, but from the mid-1990s onward agricultural production boomed, and average farm size increased markedly following a liberalization of the economy, and the massive diffusion of machinery, chemical inputs, and other agricultural technologies (Marin et al. 2105). The sector remains diverse but it has become increasingly dominated by a system of high external input commodity crop production for export. Grain and oil seed production, particularly of soya, has increased five-fold over the last three decades, partly because it has displaced other crops and expanded into what was uncultivated forest and pasture and partly because of intensification: continuous soya production is replacing crop/pasture rotation, whereas methods of production based on new forms of mechanization, the use of transgenic seed varieties, higher levels of agrochemical use, and a system of contract farming, organized by financial pools of capital have diffused widely (Phélinas and Choumert 2017).

The Argentinean seed sector consists of a mixture of domestic and foreign firms and public sector breeders. Prior to the early 1990 s, seed intellectual property rules permitted seeds to be saved and replanted by farmers and allowed seed breeders to freely use existing commercial seeds as a basis for developing improved varieties. Under that regime, a few foreign seed firms focused on the hybrid seed market (mostly maize), which offers a biological form of intellectual property protection because hybrid seed suffers a dramatic reduction in performance beyond the first generation, and so farmers have to buy hybrid seed each year. National firms and public institutions focused on nonhybrid plant varieties, such as soya, wheat, and cotton, which can readily be saved and replanted (Marin et al. 2015). National seed firms either depended on the public sector to breed new varieties and made money by multiplying, marketing, and distributing seed, or they developed new varieties themselves, relying on the ability to regularly create new improved varieties that farmers wished to purchase to make a return on their research and development costs. Multinational (MNC) seed firms gained a more prominent role in the seed market in the 1990s in the wake of the economic liberalization of the agricultural sector and the creation of an enabling regulatory regime for transgenic seeds, including changes to intellectual property rules that enabled transgenic gene sequences (and in effect the seed varieties in which those transgenes were inserted) to be patented. Domestic firms, however, have maintained a market position and strong capabilities in breeding technologies at least for some crops. Local firms typically buy genetically engineered events from, and sell domestic varieties to, MNCs and compete with them in the final market with leading positions for some crops such as soya.

We chose to focus our exploration of a T-lab based transformative space on the issue of structural change in agricultural seed markets for two reasons. First, the issue is topical. For several years now there has been a highly contested attempt in Argentina to reform and strengthen seed intellectual property rules and their enforcement, largely instigated by global agro-chemical/seed firms, but which so far has been stalled by an alliance of domestic farming interests and the Ministry of Agriculture (Marin 2015). This has provided us with a window of opportunity, both to discuss a longer-term set of implications arising from those kinds of changes, but also, importantly, to persuade busy individuals from government, business, civil society, and the public sector to give up some of their time and engage with our multistakeholder process.

Second, market concentration has not yet advanced as fast in Argentina as it has in some other countries. There is still a sizeable and successful domestic seed industry and an important public 
sector breeding presence alongside the entry in that sector of the global agro-chemical/seed firms. This means that we can explore the implications of structural change in the seed sector in a context where there are still, in principle, choices to be made.

\section{METHODS AND APPROACH}

Our approach to creating a T-lab-based transformative space has thus far been based around a two-phase process: (1) a scoping workshop designed to explore the views of a range of different actors involved in producing, using, and governing seeds, about future agricultural visions and the kinds of seed systems that could best support those visions; and (2) a codesign workshop, again with a varied group of stakeholders, intended to identify and prioritize agricultural sustainability problems associated with contemporary seed systems and identify innovations with which to collectively experiment with to address those problems.

The purpose of the initial scoping workshop was to elicit a range of views about desired social-technical-ecological futures in seed and agricultural systems. Our entry point was the contemporary debate about reforming and strengthening seed intellectual property law, and so we organized a structured World Café discussion (Brown and Isaacs 2005) around four possible scenarios related to changes to the seed law; a framing of the day which we hoped would encourage people to attend. The scenarios involved different combinations of restrictions, or the absence of restrictions, on the scope for farmers to save seeds from their own harvest and replant them without payment or permission, and the scope for seed breeders to use existing commercial seed varieties as a basis for further improvement without payment or permission. The scenarios were derived from what the researchers considered to be plausible but distinctive policy choices. The participants, who represented a wide range of institutions involved in governing, producing, and using seeds, discussed what might happen in 2030 under each of those scenarios with regard to four different meanings of, or functions played by, seeds: (1) food and supporting rural social and economic diversity; (2) technological services for industrial farmers; (3) resources for biological research and seed innovation; and (4) a source of biodiversity.

The intention was to encourage people to articulate their views about the ways in which seed systems affect different dimensions of agricultural sustainability (i.e., in ecological, economic/ developmental, and social terms) beyond the issues that were central to the public debate about reform of Argentinean seed intellectual property legislation, which were concerned with control over a black-market in seeds and seed costs. In so doing, we hoped that participants would make explicit their views about desired (i.e., sustainable) agricultural futures and the kinds of seed systems that could best support agricultural sustainability.

Prior to the second phase codesign workshop, we conducted a pilot Q method analysis of stakeholders' views about the agricultural sustainability problems associated with the current industrial structure and governance of seed systems and of possible solutions. Q method is an approach to systematically study subjective viewpoints on a topic (Eden et al. 2005). It involves asking a small, nonrepresentative but diverse group of people to rank a series of statements about a topic. The statements are drawn from interviews and/or wider policy, media, and academic debate, and in principal are selected by the researcher so as to encompass everything that has been said or written about the topic in question. The ranking is performed by each participant who sorts the set of statements from those that they most agree with to those they least agree with (and in doing so the participant explains the rationale for their ranking to the researcher). The method then looks for patterns among rankings and reduces individual rankings to a few clusters, which represent broadly shared ways of thinking about the topic. Among other things, the technique can help identify particular perspectives (or discourses) on a topic that might not otherwise be well represented in, say, public or policy debate. It can also be used to identify specific themes or issues that are critical to differentiating between different discourses, as well as those about which there is consensus across different perspectives (Barry and Proops 1999). Our pilot Q study, involving 13 interviewees (plant breeders, public officials, representatives of nongovernment organizations, and academics), was aimed at identifying the nature of competing discourses on our chosen topic and at mapping any areas of consensus among different perspectives. We planned to use this information to inform the remit and running of our codesign workshop.

The purpose of the codesign workshop was to discuss and prioritize agricultural sustainability problems associated with existing seed systems and to explore possible solutions. Our plans for the remit of the codesign workshop were made in light of the scoping phase and then subsequently modified in light of the pilot $\mathrm{Q}$ method exercise. We organized the codesign workshop as openly as possible, adopting elements of open space technology, in which participants define their own agendas on a broad theme, in this case sustainability challenges/solutions to seed market concentration (Owen 2008). We did, however, encourage participants to focus on long-term, emerging problems beyond those raised in public discussion about reform of seed intellectual property legislation, for example, by producing a short film to illustrate examples from the Latin American region of the sustainability implications of seed market concentration and strict intellectual property rules.

\section{A SCOPING WORKSHOP ON THE SEED SECTOR AND THE FUTURE OF AGRICULTURE}

The scoping workshop, held over half a day in November 2015, was intended to explore stakeholders' views about desired (sustainable) agricultural futures and the role of different kinds of seed systems in supporting or undermining those visions. The participants included: officials from the Ministry of Agriculture, the Ministry of Science, Technology and Innovation, and the National Institute of Agricultural Technology; plant breeders from both Argentinean seed firms and universities; entrepreneurs in alternative agricultural businesses; trade associations of the agricultural input industries; civil society organizations in the agricultural and rural economy sectors concerned with small farmer livelihoods and the environmental and health consequences of agricultural production; representatives of commercial farming and small family farming organizations; and members of agricultural cooperatives. The intention was to capture the diversity of opinion on agricultural sustainability from actors and institutions involved in shaping and using seed systems. The main omission was representatives of multinational seed firms who did not attend. 
Notes of the discussions from the scoping workshop revealed two utterly different perspectives. The first, which we characterized as a macro, nationalistic, market view, was concerned primarily with sustaining the existing role of the agricultural sector, through continued innovation, as a provider of strategic resources for the national economy. This perspective values agricultural production as a means of (1) generating revenue and, in particular, foreign currency to support the rest of the economy, and (2) as an opportunity to develop domestic technological capabilities and to generate linked economic activities (cf. Bisang et al. 2008). Aspects of sustainability concerning, for example the survival of smaller-scale farming and the environmental effects of intensive production were recognized by actors adopting this perspective, but it was assumed that those issues could be adequately remedied through state regulation in ways that were consistent with the continued dominance of intensive large-scale production. A prominent sustainability challenge, from this perspective, was that of concentration of knowledge, i.e., of inputs produced by very few international firms. A key issue was therefore the need to develop local production and technological capabilities to support the agricultural sector and to use those capabilities to encourage the development of other related sectors (e.g., machinery, information technology, services). This would have the effect both of diminishing the agricultural system's dependence on MNC technologies and of contributing to industrial diversification. In terms of the seed sector, the core challenge was to provide adequate support and incentives for seed innovation in the domestic private sector as opposed to reliance on international seed firms.

The second perspective, which we characterized as a local, alternative, state-centered view, was concerned primarily with enhancing the social and economic diversity of farming as a means of promoting food sovereignty and security. Intensive commodity crop production was seen as undermining and incompatible with an ecologically resilient, diverse rural social economy. In particular, current agricultural trajectories were viewed as giving rise to high levels of rural unemployment and out-migration, the forced removal of indigenous people from land, threats to the health of rural inhabitants, and severe damage to a range of ecosystem services (cf. Grau et al. 2005, Pengue 2005). Decentralized, diverse measures taken by small and medium-sized independent farmers producing food for local populations based on agro-ecological techniques and carrying out associated improvements in seeds were emphasized as key to a sustainable farming system, as was an active state providing the public goods necessary for supporting agricultural activity.

These are entirely different views about desired agricultural systems, the principal meanings or functions of seeds, and over what, in effect, the main agricultural sustainability problem(s) consist of; a divide largely mirrored in general debates about contemporary agricultural trends in Argentina (Reboratti 2010, Seghezzo et al. 2011). The workshop prompted us to reflect on a number of issues that had implications for the next phase of the project. First, it was clear from the nature of discussion during that workshop that across the two groups (as we have characterized them) there was very little patience for each other's perspectives, which were variously considered to be either naïve or uninformed/unconcerned about the social and environmental challenges of commodity crop production. Our interpretation of this phenomenon, in part, is that the structural importance of the agricultural sector is such that many of the actors who prioritize a macro, developmental set of sustainability concerns cannot envisage forms of agricultural production that differ substantially from the status quo that might point to viable pathways of change. Because activists campaigning for more diverse, smaller scale and less intensive practices generally do not address, or do not have a viewpoint about, broader macrolevel development issues, i.e., for instance about how such alternatives could become a means of economic growth, development, and diversification or how exports could be sustained through alternative practices, they tend to be ignored or dismissed as naïve even though a closer look and a more careful listen might identify some ideas and analyses about these issues (cf. IPES 2016).

Diminishing this gulf in perspectives and the failure of experimentation and policy intervention that it provokes will require, among other things, a challenge to the assertion that more sustainable agricultural practices cannot address macrodevelopment issues, such as the need to diversify productive activity or to build new export markets. It is, for example, telling that mainstream policy institutions currently view support for practices such as agro-ecological production primarily as a matter of social welfare policy, i.e., to support communities who find themselves marginalized from mainstream economic activity, rather than one of agricultural innovation per se. We think a more nuanced understanding and differentiation of the positions of different stakeholders, as we planned to explore with the Q study, as well as constructive dialogue between groups who rarely debate with or encounter each other, might help to challenge and work beyond the generalized, binary positions we observed in the scoping workshop.

A second issue, prompted in part by our experience with the preparatory workshop, was that there appeared to be few areas of actionable consensus between different kinds of stakeholders, and thus little scope for building alliances of actors to support the construction of alternative practices and pathways of change. However, despite what were in general terms competing views about the future desired role of agriculture, some issues did overlap between the two broad groups. For example, both perspectives stressed the need to support domestic capabilities in seed development as a precondition for support for any kind of desired agricultural futures; both shared the view that strict intellectual property rules, particularly patents on engineered gene sequences, were problematic in terms of preserving domestic technological capabilities; and both stressed the importance (and current absence) of public policy to establish a long-term strategy for the seed sector. Focusing discussion about potential interventions in subsequent phases of the project that at least partly address these kinds of shared concerns might therefore be more likely to capture the interest and commitment of a more plural group of actors.

One example that the research team explored in the wake of the preparatory workshop, and which addresses the shared perceived problem that patents and other strict intellectual property rules are problematic, is an open source license for seed innovation (Luby et al. 2015). The terms of such a license can require that no exclusive proprietary restrictions be imposed on seed germplasm, including any and all derivative seed varieties, in a 
way that is analogous to the arrangements governing open source software. Thus, open source licenses can create a protected commons for germplasm resources, open to all who agree not to exclusively appropriate particular varieties.

Our hypothesis was that an open source license-type arrangement might address a feature of seed-system governance that was seen as problematic across three stakeholder groups, which in other respects understand agricultural sustainability challenges in somewhat different ways. These were national seed firms, who have an interest in unhindered access to germplasm and whose business model works to an open source logic already, in the sense that those firms rely on capturing market share by innovating rapidly and regularly (i.e., by exploiting first mover advantages), rather than by preventing farmers from saving and replanting seed or restricting competitors from using germplasm as a basis for developing new varieties; parts of government concerned about the risks of overseas firms patenting and restricting access to domestic germplasm; and those of small farmers and social movements who have tended to be hostile to any form of intellectual property protection for seeds, but who otherwise wish to maintain the ability to share seeds. A germplasm commons would, of course, be inconsistent with the business models of MNC seed firms that specialize in producing genetically engineered traits, which depend on patent protection. And yet, an open-source model can function within and alongside an intellectual property regime that includes the ability to patent gene sequences (in just the same way as in the software sector, where open source production of software coexists with a proprietary industry). The idea is not therefore necessarily hugely disruptive of existing seed system configurations, and as such is not politically untenable, but it does open up space, at least in principle, for more sustainable agricultural practices. This is because the free circulation of germplasm supports the ability of farmers and seed breeders to adapt seed varieties to diverse agroecological conditions, for different agricultural production practices, to increase the within-species genetic diversity available for the development of new plant varieties, and to improve the resilience of agricultural systems. In addition, an open-source seed system potentially provides a more symbolic resource for actors seeking to experiment with more sustainable agricultural practices (beyond seed breeding per se) that have affinities with open, collaborative forms of seed production.

\section{A CODESIGN WORKSHOP}

Building on the idea of a bridging innovation designed to create a protected commons in seed germplasm, we recruited an intellectual property lawyer to work part time on our research team and we planned, initially at least, to organize a codesign workshop on that topic, i.e., focusing on exploring views about such an innovation and an exploration of the breath of likely support and strategies for creating a protected commons. The pilot Q method study, conducted prior to the planned workshop to characterize both stakeholders' views about the agricultural sustainability problems associated with the current industrial structure and governance of seed systems, and possible solutions, was intended to support the design and operation of the workshop.

Findings from the pilot Q study prompted us to alter our plans. It was clear that many of the participants we interviewed believed that seed intellectual property rights were, at most, a secondary cause of problems such as loss of agricultural biodiversity or threats to domestic technological sovereignty. Other factors were either seen as more immediately relevant, or participants refused to distinguish intellectual property rights from other aspects of the incumbent agricultural production system. Consequently, we decided there would be little purpose focusing on solutions for an issue that had not been singled out as fundamentally problematic, and therefore we broadened the remit of our planned workshop to focus more generally on identifying agricultural sustainability problems with existing seed systems and exploring an unrestricted range of possible solutions.

We held one-day workshop in April 2017, and we invited a diverse range of stakeholders, chosen, in part, because they represented key stakeholder organizations, and/or because we already had a trusted relationship with them from previous work (many had also participated in the earlier scoping workshop). Nineteen participants turned up: various public sector seed breeders, academics, an intellectual property specialist from the Ministry of Agriculture, a representative of the main seed industry trade association, a member of Congress's agriculture committee and his advisor, agro-ecological producers, members of Via Campesina, and a representative of an organization representing small and medium-sized farmers. This was a significantly narrower range of stakeholders compared with those that attended the scoping workshop, and in general it was skewed toward what we earlier termed the local, alternative, statecentered view of the future of agriculture. The organization of the event was aimed at identifying emerging problems from seed market concentration, exploring the extent to which they were at least partly shared by stakeholders, and then thinking, collectively, about interventions that might diminish those problems.

We structured the workshop into two main parts: a morning session devoted to the identification of sustainability problems by participants and the afternoon session focused on proposals to address those problems. We began the morning with a presentation of our pilot $\mathrm{Q}$ study findings and a brief video produced by the research team, which illustrated a range of effects associated with market concentration and property rights regimes in the seed sector (specifically, problems of declining agricultural biodiversity and of limits on national sovereignty in relation to domestic seed innovation). The aim was to illustrate the range of sustainability challenges associated with current trajectories in the seed sector, beyond those that were prominent in domestic public debate about reform of seed legislation. In so doing, we were directing participants' attention toward issues that we, as researchers, considered to be important, rather than allowing the group to identify and prioritize problems and solutions without our input. Likewise, in the afternoon, we were also keen that the group explored solutions that we felt might offer possible bridging qualities, such as the possibilities afforded by an open-source seed licensing idea. Clearly there is a tension here between influencing group discussions and ceding autonomy entirely to participants, although the notion of codesign suggests some balance between the input of researchers and participants.

The participants were then split into small groups representing different institutions, genders, and the kinds of discourses they most closely adopted, as revealed by the pilot Q study. Each group 
was then asked to try and arrive at a consensus about the most important sustainability challenges associated with the structure and governance of the seed system. The groups collectively identified eight sustainability problems, not all of which were necessarily directly related to the seed sector.

\section{These were:}

- the absence of political/policy clarity on what the public good in the seed and agricultural sector consists of;

- an absence of consensus on the type of agricultural model the country should adopt;

- a fundamental incompatibility between the current system of production and biodiversity;

- an absence of agricultural diversity in both biological and socioeconomic senses;

- a lack of recognition and support for the agents of informal seed improvement;

- asymmetries of power among the diversity of interests that prevail within the agricultural sector;

- the need to protect and support domestic seed technological development; and

- the need to improve access to seeds.

It is worth noting that most of these issues lie beyond the agency of a transformative space/innovation lab process in terms of what social innovations might practically achieve, but rather point to wider and deeper political programs for sustainability transformation (cf. Smith et al. 2016). In practice, the organizers chose three of those problems for group discussion in the afternoon, on the grounds that it might be possible to begin to address those problems through social innovations.

These were:

- the absence of agricultural diversity;

- the lack of recognition and support for informal seed improvement; and

- the weak protection and support for domestic seed technological development.

Participants proposed concrete solutions for the first two of those problems, but the group focusing on protection for domestic seed development failed to articulate ideas for intervention.

At a subsequent plenary session, discussion focused on the idea of creating a network of actors working on or interested in participative breeding. This proposal was supported by university-based plant breeders, scientists from the public sector research service, and rural NGOs and social movements present at the workshop. Participative breeding refers to seed breeding programs that involve close collaboration between breeders and farmers, with the latter influencing breeding priorities, and providing and selecting germplasm, for example. Typically the ambition is to support the needs of a broader range of farmers and other seed users and more diverse growing production environments than is typical in breeder-directed programs, which tend to produce varieties aimed at homogenous forms of agricultural production. The suggestion was that such a network could be used to experiment with a range of initiatives linked to improving support for participative breeding: (1) mapping of national and regional initiatives in participative breeding; (2) supporting capacity building in participative breeding; (3) obtaining certification for the outputs of participative breeding; (4) creating a market for the products of such seeds, when used in practices such as agro-ecological and fair trade production; and (5) creating an open-source license or pledge for germplasm produced through participative breeding.

In retrospect, the remit was ambitious for a one-day event. One option might have been to stretch the event over a longer time frame, but that would not have been possible for most of the participants, especially those in relatively senior, national-level roles. Nor would a longer event have necessarily overcome the chasm between different perspectives, which has a long history and is rooted in deeply embedded institutional commitments. However, compressing so much into one day had a number of drawbacks. We found it difficult to document what was being said in simultaneous group discussions, and to find sufficient time to explore, for example, why people thought that particular problems or solutions were or were not desirable, what their opinions on the underlying drivers of problems were, or to return to points in greater depth as discussions veered over a wide range of issues.

Another difficulty was that identifying shared views and common positions across the heterogeneous group of stakeholders was challenging, even though we had a narrower range of stakeholders than were present at our earlier scoping workshop. Dialogue and debates were cordial, but the underlying tensions were obvious when trying to identify shared problems. It was useful to have performed the pilot Q study. This allowed us to map the issue terrain prior to the T-Lab and to identify points of connection and contestation between different actors. For example, it helped us recognize that agricultural biodiversity loss was almost universally seen as problematic across different stakeholders and that actors' viewpoints were not necessarily correlated with their institutional home. Conflicts diminished in the afternoon, in part because a few people (who were more closely associated with the macrodevelopmental view of agricultural sustainability) left after lunch, but also because we allowed people to self-organize into groups for the afternoon session.

Despite these occasional tensions, bringing together different kinds of stakeholders was productive insofar as we managed to link people with scientific expertise, those with the authority resources of government, agro-ecological producers, and representatives of rural social movements, all of who were interested in creating practical measures to support participative seed breeding. During the day, several participants also emphasized that there was no other space, whether within formal policy processes or elsewhere, for discussing agricultural sustainability issues in relation to the seed sector. The challenge, at this point in the project, is to put into working practice one or more of the proposals identified at the codesign workshop and to persuade the different actors who expressed interest in the initiative to continue to devote time and energy into supporting one or more of the measures we try to pilot.

Taking forward the project is challenging, in part because, as researchers, we have to be flexible and capable enough to take it in directions that we could not anticipate at the beginning of the 
project, but which rather are identified with stakeholders as the project progresses. This is what codesign entails but we are likely to be faced with several practical problems, such as the need to recruit people with particular skill sets as the project progresses and changes.

Moving beyond the first codesign event is likely to also imply or involve what appears to be taking sides. The ambition to support participative plant breeding and the alliance of actors that we have identified interested in that objective is only a partial representation of the diversity of actors and their perspectives. Further collaborative work on that issue will involve excluding some stakeholders. Given that the idea is transformation for sustainability and involves some clear principles about justice and environment, this is quite reasonable, but it will be important to try and keep dialogue open with nonparticipants/nontransformers, even if we recognize that there are limits to consensus-based approaches.

\section{DISCUSSION AND CONCLUSIONS}

Reflecting on our experience highlights two issues that we think are relevant to the creation and support of facilitated transformative spaces. The first issue is that in the agricultural domain in Argentina, as in many other arenas where sustainability problems arise, stakeholders' views about what needs to be sustained, for whom, why, and how are ambiguous and highly contested. Guidance on running social transformation/change labs suggests that obtaining a shared understanding of problems and of visions for more desirable futures (typically an early stage in the lab process) is feasible, if not necessarily straightforward. The claim is that this requires ensuring that the diverse perspectives of actors are incorporated into a common conversation, and that techniques are used to encourage actors to unfreeze their assumptions and see systems and problems from each other's perspectives (REOS 2013, Westley et al. 2014). We are less convinced that obtaining a shared understanding of sustainability problems and solutions is feasible; at least for the kinds of issues we are focusing on, in which a classic divide exists between national economic development aspects of sustainability and the ecological and local social justice dimensions. Although a partial reframing of issues might be possible (e.g., our earlier example of persuading mainstream policy institutions to treat agro-ecological production as an issue of agricultural innovation rather that only a matter of social welfare policy), our experience is of the absence of, and sheer difficulty in obtaining, a shared understanding of which meanings or functions of seed systems are most important, of the agricultural sustainability problems associated with existing seed systems, and of desired agricultural futures. Indeed, that absence lies at the heart of the broader transformation challenge.

The second issue, and again relevant to many other arenas beyond our problem space, is that actors who support and/or are trying to promote alternative pathways of change, at least in relation to the kinds of normative sustainabilities that we as researchers were sympathetic with, are politically highly marginalized by comparison with the actors and constituencies that constitute existing, well-established agricultural production systems. The innovation lab literature, by dint of the fact that it assumes that substantial consensus is possible among a representative group of stakeholders concerning problem definitions and desired future systems, glosses over this issue, even if it recognizes that incumbent institutions and practices are difficult to shift.

We have tried to grapple explicitly with both of those issues. The extent to which and the ways in which framings of sustainability are contested may not be obvious when convening a transformative space, especially if some perspectives, which are absent in wider public or policy debate, are not included in the process. Our scoping workshop, involving a wide range of stakeholders and no predefinition of what we or others meant by sustainability, helped to capture some of the diversity of perspectives on our topic, as did the pilot $\mathrm{Q}$ analysis, which represented a more formal way of trying to document the breadth of meaning of sustainability in relation to agricultural and seed systems.

Responding to deeply contested perspectives on agricultural and seed-system sustainability might take several forms. One option is to decide which framings(s) of sustainability ought to be prioritized and pursued, exclude some actors, and work with a more aligned group of stakeholders who already broadly share those perspectives. Another is to foster a process of negotiation and learning to try and shift perspectives or reframe the ways in which problems are understood among the different actors and constituencies. A third option is to identify those aspects of a problem in which there is greater consensus as a basis for thinking about novel solutions, or to explore interventions that are attractive to actors who understand and prioritize sustainability challenges in different ways.

The first option, that of working with a more aligned group of stakeholders, is certainly viable, yet, the risk is that researcherfacilitated transformative spaces end up working only with actors that are politically marginal in relation to the wider systems they seek to transform. Proposed ideas and solutions may, as a consequence, either be difficult to put into working practice, or may remain a niche endeavor with little potential to reconfigure wider seed and agricultural systems, or they may simply reproduce what organized civil society groups are doing anyway. Our second workshop ended with a more homogenous group of actors than we had intended because of self-exclusion and for this reason, it will be important to maintain communication with other seedsystem stakeholders and explore whether we can enroll actors with complementary resources to support whatever ideas we try to put into practice.

The second option, of trying to reframe the ways in which problems are understood among different actors and constituencies, holds significant potential. Indeed, in our view, intensive commodity crop production in Argentina is so deeply entrenched, i.e., institutionally, economically, politically, and discursively, that actors trying to promote more sustainable agricultural practices are only likely to be supported more widely if parts of the domestic private sector and the state can be persuaded that current agricultural trajectories pose threats to their own interests, for example, on the grounds that the agricultural sector as a whole is becoming less economically resilient and/or that it may end up destroying domestic technological capabilities. However, efforts to reframe problems and/or actors' perceptions of their interests in relation to those problems would probably require a different format for running a transformative space than we were able to adopt, involving more 
time together and more intense facilitation. It would also involve activities that lie well beyond the agency of a series of workshops and events, such as more general campaigning, academic, media, and policy intervention. These kinds of broader activities can nevertheless be recognized, documented, discussed, and maybe even mobilized around within relatively brief, facilitated transformative spaces, even if acting on such knowledge demands wider political action for sustainability transformations.

We tried to focus on the third option, i.e., that of identifying aspects of sustainability problems that were shared across different stakeholders, as a basis for thinking about novel interventions and/or to explore innovations that are attractive to actors who otherwise understand and prioritize sustainability problems and desired solutions in different ways. A large part of the rational is that coalitions of actors are more likely to successfully challenge and foster structural change in pervasive social-technical systems. Put simply, those advocating for alternative, more ecologically benign and socially just pathways of change need more powerful allies who command resources such as those of legitimacy (i.e., state institutions), expertise, organizational capacity, and finance.

The initial multistakeholder scoping workshop helped us to better appreciate areas of conflict and consensus with regard to different actors' perspectives on agricultural sustainability. It helped us to think about affinities between different groups and the kinds of social innovation they might variously align with, hence our proposal to explore the idea of creating a protected commons in germplasm via an open-source seed licensing system. It remains to be seen whether that idea (among several that were highlighted in the codesign workshop) can be put into working practice and how far it might gain traction among different kinds of stakeholders. Within our workshop, the idea resonated with a small number of university-based seed breeders, rural NGOs, agro-ecological producers, and scientists from the government's agricultural research service, but we will need wider support among such constituencies and, ideally, interest from some domestic private sector seed firms, if the proposal is to really succeed. The broader point is that smart alliances between actors, formed around ideas for novel interventions that can bridge the interests and perspectives of different constituencies, point to strategies for reconfiguring the social relations around seed systems, in ways that might limit the restructuring processes driven by global firms, and that might help open up space for more sustainable pathways of agricultural change.

Responses to this article can be read online at: http://www.ecologyandsociety.org/issues/responses. php/10033

\section{Acknowledgments:}

The authors thank two anonymous reviewers for their contributions to drafts of this manuscript. This work is based on research supported in part by the Transformations to Sustainability Programme, which is coordinated by the International Social Science Council and funded by the Swedish International Development Cooperation Agency, and implemented in partnership with the National Research Foundation of South Africa (Grant Number SSC2015-TKN150224114426). The Transformations to Sustainability Programme represents a contribution to Future Earth.

\section{LITERATURE CITED}

Barry, J., and J. Proops. 1999. Seeking sustainability discourses with Q methodology. Ecological Economics 28:337-345. http://dx. doi.org/10.1016/S0921-8009(98)00053-6

Bisang, R., G. Anlló, and M. Campi. 2008. Una revolución (no tan) silenciosa. Claves para repensar el agro en Argentina. Desarrollo Económico 48:165-207.

Brown, J., and D. Isaacs. 2005. The world café: shaping our futures through conversations that matter. Berrett-Koehler, San Francisco, California, USA.

Eden, S., A. Donaldson, and G. Walker. 2005. Structuring subjectivities? Using Q methodology in human geography. Area 37:413-422. http://dx.doi.org/10.1111/j.1475-4762.2005.00641.x

Future Earth. 2014. Strategic research agenda 2014: priorities for a global sustainability research strategy International Council for Science (ICSU), Paris, France. [online] URL: http://futureearth. org/sites/default/files/strategic research agenda 2014.pdf

Grau, H. R., T. M. Aide, and N. I. Gasparri. 2005. Globalization and soybean expansion into semiarid ecosystems of Argentina. Ambio 34:265-266. http://dx.doi.org/10.1579/0044-7447-34.3.265

Gryszkiewicz, L., I. Lykourentzou, and T. Toivonen. 2016. Innovation labs: leveraging openness for radical innovation? Journal of Innovation Management 4(4).

Hassan, Z. 2014. The social labs revolution: a new approach to solving our most complex challenges. Berrett-Koehler, San Francisco, California, USA.

Howard, P. H. 2015. Intellectual property and consolidation in the seed industry. Crop Science 55(6):2489-2495. http://dx.doi. org/10.2135/cropsci2014.09.0669

International Panel of Experts on Sustainable Food Systems (IPES-Food). 2016. From uniformity to diversity: a paradigm shift from industrial agriculture to diversified agroecological systems. International Panel of Experts on Sustainable Food Systems. [online] URL: http://www.ipes-food.org/images/Reports/ UniformityToDiversity FullReport.pdf

International Social Science Council (ISSC)/United Nations Educational, Scientific and Cultural Organisation (UNESCO). 2013. World social science report 2013: changing global environments. Organisation for Economic Co-operation and Development (OECD) and UNESCO, Paris, France. [online] URL: http://unesdoc.unesco.org/images/0022/002246/224677e. pdf

Lockwood, M. 2014. The political dynamics of green transformations: the roles of policy feedback and institutional context. EPG Working Paper 1403. University of Exeter, Exeter, UK. [online] URL: http://projects.exeter.ac.uk/igov/wp-content/ uploads/2014/04/WP-8-The-political-dynamics-of-green-transformations. pdf 
Luby, C. H., J. Kloppenburg, T. E. Michaels, and I. L. Goldman. 2015. Enhancing freedom to operate for plant breeders and farmers through open source plant breeding. Crop Science 55:2581-2488. http://dx.doi.org/10.2135/cropsci2014.10.0708

Marin, A. 2015. El futuro de las semillas y la agricultura en América Latina. Ciencia e Investigación 65:84-93.

Marin, A., L. Navas-Alemán, and C. Perez. 2015. Natural resource industries as a platform for the development of knowledge intensive industries. Tijdschrift voor Economische en Sociale Geografie 106(2):154-168. http://dx.doi.org/10.1111/ tesg. 12136

Moore, M.-L., O. Tjornbo, E. Enfors, C. Knapp, J. Hodbod, J. A. Baggio, A. Norström, P. Olsson, and D. Biggs. 2014. Studying the complexity of change: toward an analytical framework for understanding deliberate social-ecological transformations. Ecology and Society 19(4):54. http://dx.doi.org/10.5751/ ES-06966-190454

Newell, P. 2015. The politics of green transformations in capitalism. Pages 68-85 in I. Scoones, M. Leach, and P. Newell, editors. The politics of green transformations. Routledge/ Earthscan, London, UK.

Newell, P., and R. Mackenzie. 2004. Whose rules rule? Development and the global governance of biotechnology. IDS Bulletin 35:82-91. http://dx.doi.org/10.1111/j.1759-5436.2004. $\underline{\text { tb00111.x }}$

O’Brien, K. 2012. Global environmental change II: from adaptation to deliberate transformation. Progress in Human Geography 36:667-676. https://doi.org/10.1177/0309132511425767

Olsson, P., V. Galaz, and W. J. Boonstra. 2014. Sustainability transformations: a resilience perspective. Ecology and Society 19 (4):1. http://dx.doi.org/10.5751/ES-06799-190401

Olsson, P., M.-L. Moore, F. R. Westley, and D. D. P. McCarthy. 2017. The concept of the Anthropocene as a game-changer: a new context for social innovation and transformations to sustainability. Ecology and Society 22(2):31. http://dx.doi. org/10.5751/ES-09310-220231

Owen, H. 2008. Open space technology: a user's guide. BerrettKoehler, San Francisco, California, USA.

Patterson, J., K. Schulz, J. Vervoort, S. van der Hel, O. Widerberg, C. Adler, M. Hurlbert, K. Anderton, M. Sethi, and A. Barau. 2017. Exploring the governance and politics of transformations towards sustainability. Environmental Innovation and Societal Transitions 24:1-16. http://dx.doi.org/10.1016/j.eist.2016.09.001

Pelling, M., K. O'Brien, and D. Matyas. 2015. Adaptation and transformation. Climatic Change 133:113-127 http://dx.doi. org/10.1007/s10584-014-1303-0

Pengue, W. A. 2005. Transgenic crops in Argentina: the ecological and social debt. Bulletin of Science, Technology and Society 25:314-322. http://dx.doi.org/10.1177/0270467605277290

Pereira, L., T. Karpouzoglou, S. Doshi, and N. Frantzeskaki. 2015. Organising a safe space for navigating social-ecological transformations to sustainability. International Journal of Environmental Research and Public Health 12(6):6027-6044. http://dx.doi.org/10.3390/ijerph120606027
Phléinas, P., and J. Choumert. 2017. Is GM soybean cultivation in Argentina sustainable? World Development 99:452-462. http:// dx.doi.org/10.1016/j.worlddev.2017.05.033

Piesse, J., and C. Thirtle. 2010. Agricultural R\&D, technology and productivity. Philosophical Transactions of the Royal Society B 365:3035-3047. http://dx.doi.org/10.1098/rstb.2010.0140

Reboratti, C. E. 2010. Un mar de soja: la nueva agricultura en Argentina y sus consecuencias. Revista de geografia Norte Grande 45:63-76. http://dx.doi.org/10.4067/S0718-34022010000100005

REOS. 2013. The Reos change lab addressing complex challenges with social innovation. REOSpartners. [online] URL: http://sociallabs.org/wp-content/uploads/2014/12/20130213_McConnell-FormattedFinal-Draft.pdf

Rip, A., and R. Kemp. 1998. Technological change. Pages 327-399 in S. Rayner and E. L. Malone, editors. Human choice and climate change: resources and technology. Volume II. Battelle, Columbus, Ohio, USA.

Schmitz, H., and I. Scoones. 2015. Accelerating sustainability: why political economy matters. IDS Evidence Report 152. Institute of Development Studies, Brighton, UK.

Schenkelaars, P., H. de Vriend, and N. Kalaitzandonakes. 2011. Drivers of consolidation in the seed industry and its consequences for innovation. Report for COGEM (Commissie Genetische Modificatie). Schenkelaars Biotechnology Consultancy, Wageningen, The Netherlands. [online] URL: https://www.lisconsult.nl/files/ docs/consolidation seed industry.pdf

Scoones, I., M. Leach, and P. Newell. 2015. The politics of green transformations. Routledge/Earthscan, London, UK.

Seghezzo, L., J. N. Volante, J. M. Paruelo, D. J. Somma, E. C. Buliubasich, H. E. Rodríguez, S. Gagnon, and M. Hufty. 2011. Native forests and agriculture in Salta (Argentina): conflicting visions of development. Journal of Environment and Development 20(3):251-277. http://dx.doi.org/10.1177/1070496511416915

Simoes, A., D. Landry, C. Hidalgo, and M. Teng. 2017. Observatory of economic complexity (Argentina). Observatory of Economic Complexity. [online] URL: https://atlas.media.mit. edu/en/profile/country/arg

Smith, A. 2007. Translating sustainabilities between green niches and sociotechnical regimes. Technology Analysis and Strategic Management 19(4):427-450. http://dx.doi.org/10.1080/09537320701403334

Smith, A., T. Hargreaves, S. Hielscher, M. Martiskainen, and G. Seyfang. 2016. Making the most of community energies: three perspectives on grassroots innovation. Environment and Planning A 48:407-432. http://dx.doi.org/10.1177/0308518X15597908

Smith, A., and A. Stirling. 2010. The politics of social-ecological resilience and sustainable socio-technical transitions. Ecology and Society 15(1):11. [online] URL: http://www.ecologyandsociety. org/vol15/iss1/art11/

Smith, A., A. Stirling, and F. Berkhout. 2005. The governance of sustainable socio-technical transitions. Research Policy 34:1491-1510. http://dx.doi.org/10.1016/j.respol.2005.07.005 
Stirling, A. 2009. Direction, distribution, diversity! Pluralising progress in innovation, sustainability and development. STEPS Working Paper 32. STEPS Centre, Brighton, UK. [online] URL: http://steps-centre.org/wp-content/uploads/stirling-paper-32.pdf

Stirling, A. 2014. Emancipating transformations: from controlling 'the transition' to culturing plural radical progress. STEPS Working Paper 64. STEPS Centre, Brighton, UK. [online] URL: https:// steps-centre.org/wp-content/uploads/Transformations.pdf

Westley, F., S. Goebey, and K. Robinson. 2012. Change lab/design lab for social innovation: a thought piece for the development of a new approach for building capacity for social innovation in Canada. Waterloo Institute for Social Innovation and Resilience, Waterloo, Ontario, Canada. [online] URL: https://uwaterloo.ca/ waterloo-institute-for-social-innovation-and-resilience/sites/ca.waterlooinstitute-for-social-innovation-and-resilience/files/uploads/files/change lab. pdf

Westley, F., S. Laban, C. Rose, K. McGowan, K. Robinson, O. Tjornbo, and M. Tovey. 2014. Social innovation lab guide. University of Waterloo, Waterloo, Ontario, Canada. [online] URL: https://uwaterloo.ca/waterloo-institute-for-social-innovationand-resilience/sites/ca.waterloo-institute-for-social-innovation-andresilience/files/uploads/files/10_silabguide final.pdf" target=" blank

Westley, F., P. Olsson, C. Folke, T. Homer-Dixon, H. Vredenburg, D. Loorbach, J. Thompson, M. Nilsson, E. Lambin, J. Sendzimir, B. Banarjee, V. Galaz, and S. van der Leeuw. 2011. Tipping towards sustainability: emerging pathways of transformation. Ambio 40:762-780. http://dx.doi.org/10.1007/s13280-011-0186-9 